\title{
Design and Implementation of PWM Charge Controller and Solar Tracking System
}

\author{
Bishwajit Swarnakar', Anupama Datta ${ }^{2}$ \\ ${ }^{1,2}$ Department of Electrical and Electronic Engineering, Leading University, VIP Road, Sylhet 3100, Bangladesh
}

\begin{abstract}
The main object of this paper is to report and present the design and implementation of PWM based solar tracking system. Solar tracking allows more energy to be produced because the solar array is able to remain aligned to the sun. Our final goal is to develop an automatic tracking system which will keep the solar panels aligned with the sun in order to maximize efficiency. In this project we are trying to increase the solar power production and safety of solar power system. This project has two deferent parts those are solar tracker and PWM charge controller. We have tried to make a tracker which can track more sun intensity for the solar panel. For using the solar tracker system we can produce more energy than the analog solar system. In this project we have also tried to generate more efficiency than the other solar system by the PWM charge controller. Without charging the battery from the solar panel, the PWM charge controller made by us gives various kinds of protection like as night prevent current protection, load control, over charge control, show battery charge level and short circuit protection.
\end{abstract}

Keywords: Solar Energy, Tracker, PWM, Charge Controller

\section{Introduction}

This solar energy is considered a great source for tackling this crisis. But the rural people are not economically solvent enough to use large solar panels to get more electricity for running their everyday needs [1]. The solar energy is directly converted into electrical energy by solar photovoltaic modules. The main factors that affect the efficiency of the collection process are solar cell efficiency, intensity of source radiation and storage techniques. The efficiency of a solar cell is limited by materials used in solar cell manufacturing. It is particularly difficult to make considerable improvements in the performance of the cell, and hence restricts the efficiency of the overall collection process. Therefore, the increase of the intensity of radiation received from the sun is the most attainable method of improving the performance of solar power. Solar panels are installed at a tilt angle of $23^{\circ}$ in Bangladesh, though this alignment depends upon the installations geographic location. These panels are fixed facing south to get adequate sunlight all the year round. During winter season the panel will generate minimum power only from diffused sunlight in the morning and late afternoon since the sunlight falls transversely at that time. So tilt angle of the solar panel should be around $45^{\circ}$ to achieve maximum output power during day time in winter. In this paper we have discussed the techniques to increase the light gathering ability of a solar by using solar tracking system and PWM charge controller. We have also try to improve the efficiency of the solar system by using PWM. In Bangladesh which charge controllers are found those are made by analog system with 7 segment display. As a result made of charge controller by using analog system, the efficiency of controller is less than the other controller. We have generated PWM by using microcontroller. Because of the full system is controlled by microcontroller, the efficiency of controller is more than the analog system. The solar power system which are seen in

Bangladesh at present, are placed in a fixed angle [13]. As a result the solar power system sometimes generate less power or sometimes does not generate any power in a particular time of the day. To get rid of this problem we have made the solar tracking system. The solar panel changes its position with the movement of the sun. Because of the facility of changing position, it can generate more power than the general solar system.

\section{Working Process}

The complete procedure can be divided into two major parts: Solar Tracker and PWM Charge Controller.

\subsection{Flowcharts of Solar Tracking System}

In the initial test, the sensor circuit and motor was used to track the sun for a full day. The sensor was mounted on a panel and the motor would rotate the panel to face the sun. The panel would rotate a few degrees at varying time intervals. The setup rotated about $235^{\circ}$ for the full day. It was not able to track the sun the next day due to the sensors facing the opposite direction of the sunrise. When sensors detect the sun then it sends a value into the microcontroller. When microcontroller gets those values from sensor then microcontroller use a comparator function and take a decision which sensor has more sun intensity. Thus the panel starts move on this position.

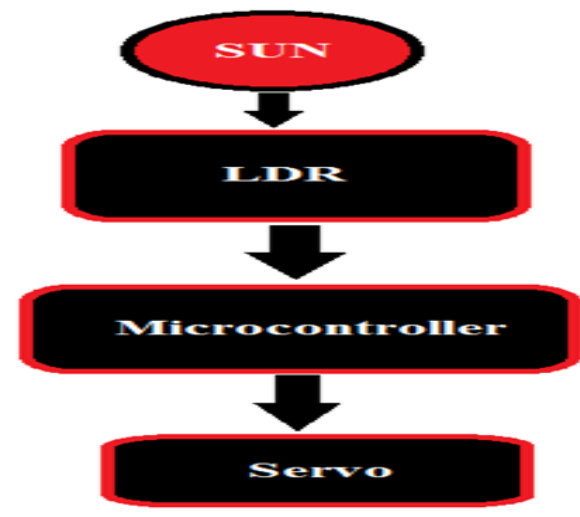

Figure 1: Flowcharts of solar tracker 


\section{International Journal of Science and Research (IJSR) \\ ISSN (Online): 2319-7064}

Index Copernicus Value (2013): 6.14 | Impact Factor (2015): 6.391

\subsection{Flowcharts of Pulse Width Modulation (PWM) Charge Controller}

When solar cell gets proper photon energy then it makes electrical power. It could be approximately $20 \mathrm{~V}$. So, we need to do control the high current \& voltage. For this reason we use PWM charge controller system. This controller works like: When solar cell produces voltage then this voltage detect by a voltage indicator. After this measurement the voltage control by a voltage controller and using this voltage we can charge our panels battery.

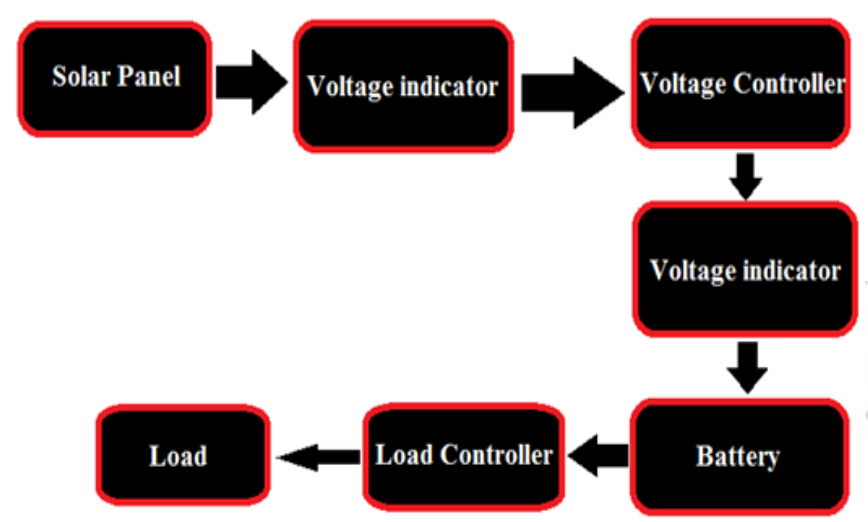

Figure 2: Flowcharts of pulse width modulation (PWM) charge controller

\section{Design \& Implementation}

The overall goal of this project was to design and implementation of solar Tracker with PWM charge controller. The tracker uses the sun sensor to follow the sun across the sky throughout the day. While building the tracker, we did some additional physical analysis of the design.

\subsection{Design of the Solar Tracker}

A solar tracker is a device for orienting a solar photovoltaic panel, day lighting reflector or concentrating solar reflector or lens toward the sun [16]. Solar (or photovoltaic) cells convert the suns energy into electricity. Sunlight is composed of miniscule particles called photons, which radiate from the sun. As these hit the silicon atoms of the solar cell, they transfer their energy to lose electrons, knocking them clean off the atoms. When sunlight focus on LDR1 then the servo motor holds its position at $85^{\circ}$. This angle for the time 6.00 am to $11.00 \mathrm{am}$. Secondly, when sunlight focus on LDR2 then the servo motor holds its position at $65^{\circ}$. This angle for the time 11.00 am to $1.00 \mathrm{pm}$. Thirdly, when sunlight focus on LDR3 then the servo motor holds its position at $50^{\circ}$. This angle for the time $1.00 \mathrm{pm}$ to $3.00 \mathrm{pm}$. And at last when sunlight focus on LDR4 then the servo motor holds its position at $35^{\circ}$. This angle for the time $3.00 \mathrm{pm}$ to night. At night the servomotor holds its position at $85^{\circ}[21]$.

\subsection{Design of PWM Based Solar Charge Controller}

Pulse Width Modulation (PWM) is the most effective means to achieve constant voltage battery charging by switching the solar system controllers power devices [16]. When in PWM regulation, the current from the solar array tapers according to the battery's condition and recharging needs. The heart of the charge controller is Arduino nano board. The arduino MCU senses the solar panel and battery voltages. According to these voltages it decides how to charge the battery and control the load. The amount of charging current is determined by difference between battery voltage and charge set point voltages. The controller uses two stages charging algorithm. According to the charging algorithm it gives a fixed frequency PWM signal to the solar panel side pMOSFET. The frequency of PWM signal is $490.20 \mathrm{~Hz}$ (default frequency for pin-3). The duty cycle $0-100 \%$ is adjusted by the error signal [14]. The controller gives HIGH or LOW command to the load side p-MOSFET according to the dusk/dawn and battery voltage.

The charge controller is designed by taking care of the following points:

1)Prevent Battery Overcharge: To limit the energy supplied to the battery by the solar panel when the battery becomes fully charged. This is implemented in charge cycle ( ) of my code.

2)Prevent Battery over discharge: To disconnect the battery from electrical loads when the battery reaches low state of charge. This is implemented in load control () of my code.

3)Provide Load Control Functions: To automatically connect and disconnect an electrical load at a specified time. The load will ON when sunset and OFF when sunrise. This is implemented in load control () of my code.

4)Monitoring Power and Energy : To monitor the load power and energy and display it.

5)Protect from abnormal Condition: To protect the circuit from different abnormal situation like lightening, over voltage, over current and short circuit etc.

6)Indicating and Displaying: To indicate and display the various parameters.

7)Serial Communication: To print various parameters in serial monitor.

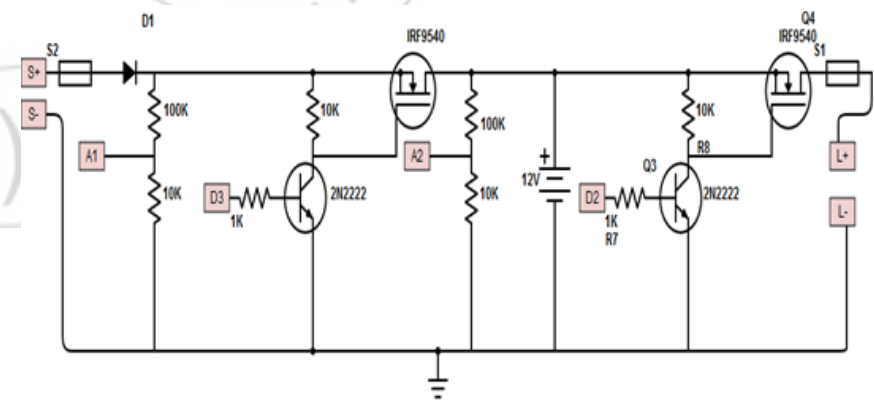

Figure 3: Circuit diagram of the PWM charge controller 


\section{International Journal of Science and Research (IJSR) \\ ISSN (Online): 2319-7064}

Index Copernicus Value (2013): 6.14 | Impact Factor (2015): 6.391

\subsection{Charging Algorithm}

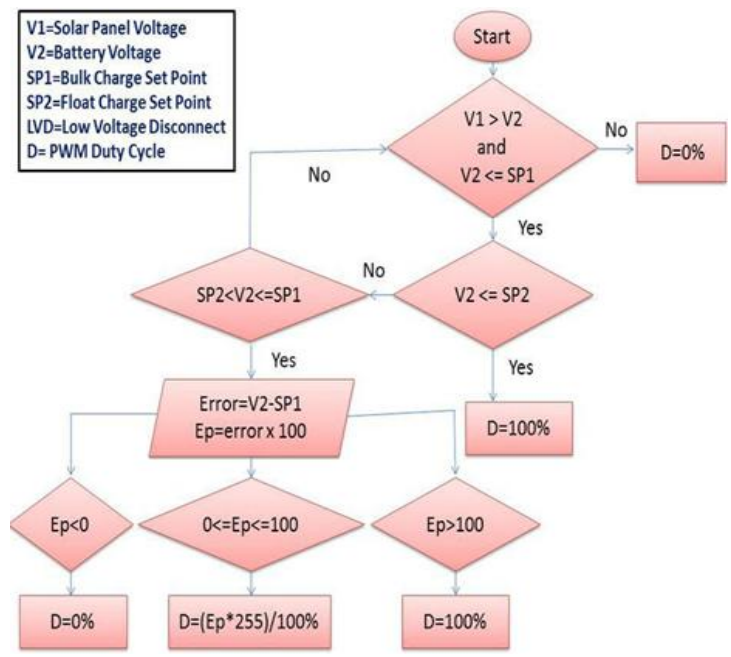

Figure 4: Charging Algorithm of the pwm charge controller.

\section{Measurement \& Calculation}

After designing of the solar tracker, we have measured and calculated the rating of voltage, current and power.

\subsection{Voltage Measurement}

Arduinos analog inputs can be used to measure DC voltage between 0 and $5 \mathrm{~V}$ (when using the standard $5 \mathrm{~V}$ analog reference voltage) and this range can be increased by using two resistors to create a voltage divider. The voltage divider decreases the voltage being measured to within the range of the Arduino analog inputs. We can use this to measure the solar panel and battery voltages.

For a voltage divider circuit

Vout $=\mathrm{R} 2 /(\mathrm{R} 1+\mathrm{R} 2) \times \mathrm{Vin}$ Vin $=(\mathrm{R} 1+\mathrm{R} 2) / \mathrm{R} 2 \times$ Vout

The analogRead() function reads the voltage and converts it to a number between 0 and 1023 .

\section{Calibration:}

Were going to read output value with one of the analog inputs of Arduino and its analog Read () function. That function outputs a value between 0 ( $0 \mathrm{~V}$ in input) and 1023 ( $5 \mathrm{~V}$ in input) that is $0,0049 \mathrm{~V}$ for each increment (As $5 / 1024$ $=0.0049 \mathrm{~V})$.

Vin $=$ Vout $*(\mathrm{R} 1+\mathrm{R} 2) / \mathrm{R} 2 ; \mathrm{R} 1=100 \mathrm{k}$ and $\mathrm{R} 2=20 \mathrm{k}$

Vin $=$ ADC count $* 0.0049 *(120 / 20)$ Volt // Highlighted part is Scale factor

\subsection{Current Measurement}

For current measurement I used a Hall Effect current sensor ACS 712 (5A). The ACS712 sensor read the current value and converts it into a relevant voltage value, The value that links the two measurements is sensitivity.

As per data sheet for a ACS 712 (5A) model : 1. Sensitivity is $185 \mathrm{mV} / \mathrm{A}$. 2. The sensor can measure positive and negative currents (range-5A-5A). 3. Power supply is 5V. 4. Middle sensing voltage is $2.5 \mathrm{~V}$ when no current.

\section{Overall Efficiency of the System}

Without PWM Charge Controller and Tracking System the change of storage charges.

\begin{tabular}{|c|c|c|}
\hline Time & Change of Charge & Difference \\
\hline 9am to $10 \mathrm{am}$ & $58 \%$ to $62 \%$ & $4 \%$ \\
\hline $11 \mathrm{am}$ to $12 \mathrm{pm}$ & $65 \%$ to $70 \%$ & $5 \%$ \\
\hline $1 \mathrm{pm}$ to $2 \mathrm{pm}$ & $73 \%$ to $79 \%$ & $6 \%$ \\
\hline 3pm to $4 \mathrm{pm}$ & $85 \%$ to $90 \%$ & $5 \%$ \\
\hline
\end{tabular}

Average change of charge for an hour is $5 \%$

With the PWM Charge Controller and Tracking System the change of storage charges.

\begin{tabular}{|c|c|c|}
\hline Time & Change of Charge & Difference \\
\hline 9am to $10 \mathrm{am}$ & $52 \%$ to $61 \%$ & $9 \%$ \\
\hline $11 \mathrm{am}$ to $12 \mathrm{pm}$ & $63 \%$ to $72 \%$ & $9 \%$ \\
\hline 1pm to $2 \mathrm{pm}$ & $75 \%$ to $84 \%$ & $9 \%$ \\
\hline 3pm to $4 \mathrm{pm}$ & $91 \%$ to $100 \%$ & $9 \%$ \\
\hline
\end{tabular}

Average change of charge for an hour is $9 \%$

So that, PWM Charge Controller with Tracking System is 4\% more efficient than Without PWM Charge Controller and Tracking System.

\section{Future Development}

This project can be improved by MPPT system. Maximum Power Point Tracking (MPPT) is a technique that grid connected inverters, solar battery chargers and similar devices use to get the maximum possible power from one or more photovoltaic devices, typically solar panel though optical power transmission systems can benefit from similar technology. We can also plan to improve the system where whole tracking device will move on straight along $\mathrm{X}$-axis with movement of the sun. It will help to get more sunlight without any reflection.

\section{Conclusion}

Renewable energy solutions are becoming increasingly popular. Photovoltaic or solar systems are one good example of this [19]. In order to maximize power output from the solar panels, one needs to keep the panels aligned with the sun. This is a far more cost effective solution than purchasing additional solar panels when dealing with large panel arrays. This project develops solar tracking system with PWM which will keep the solar panels aligned with the sun in order to maximize efficiency.PWM charge controller is best for us which is treated as the first significant advance in solar battery charging. It increases efficiency of our solar system. We can see the world energy resources depletion to be a major problem \& global warming, which is a major concern. Switching to solar power, which is clean and green and enhancing its efficiency by using sun trackers is a great option in the near future. To conclude, this project turned out well and met the original requirements and functionality. Although there were many problems and more work on the mechanical side than originally expected, overall it was an enjoyable experience completing this project. 


\section{International Journal of Science and Research (IJSR) \\ ISSN (Online): 2319-7064}

Index Copernicus Value (2013): 6.14 | Impact Factor (2015): 6.391

\section{References}

[1] Shakir-ul-haque Khan,Towfiq-ur-Rahman,and Shahadat Hossain, A Brief Study of the Prospect of Solar Energy in Generation of Electricity in Bangladesh, Journal of Selected Areas in Renewable and Sustainable Energy (JRSE), June Edition, 2012.

[2] "Get The Most Power Out Of Your Solar Panels With A Solar Panel Tracking System ".Easy Wind Power and Solar Power Solutions For Your Home and Remote Getaways.Web.26 May 2010. <http://easysolarpowerkit.com/solar-paneltracking

[3] Book "Renewable Energy Technologies "by Chetan Singh Solanki.

[4] "Assignment of Renewable Energy Resources "of Bangladesh by Mazharul Islam.

Hoppe, H. and N.S. Sariciftci, Organic solar cells: An overview. Journal Of Materials Research, 2004. 19(7): p. 1924-1945

[5] Gregg, B.A.,The photoconversion mechanism of excitonic solar cells. Mrs Bulletin, 2005. 30(1): p. 2022.

[6] Toothman, Jessika, and Scott Aldous. "How Solar Cells Work". HowStuffWorks.com. Discovery Communications, LLC, 2010. Web. 11 Oct.2011. <http:science.howstuffworks.com/environmental/energy /solar-cell3.htm>.

[7] Simon, J. and J.J. Andre, Molecular semiconductors. 1985, Berlin-Heidelberg: Springer- Verlag. 142.

[8] Kacira, M (2004)."Determining optimum tilt angles and orientations of photovoltaic panels in Sanliurfa, Turkey". Renewable energy (0960-1481), 29 (8), p. 1265.

[9] http://phindia.com/bookdetails/Renewable-energysources-and-emergingtechnologies by-kothari.

[10] "Photovoltaics". Wikipedia, the Free Encyclopedia. Web. 01 June 2010. <http://en.wikipedia.org/wiki/Photovoltaics>.

[11] Halls, J.J. and R.H. Friend, Organic Photovoltaic devices, in Clean electricity from photovoltaics, M.D. Archer and R. Hill, Editors. 2001, Imperial College Press: London.

[12] "Photovoltaics". Wikipedia, the Free Encyclopedia. Web. $01 \quad$ June June 2010. <http://en.wikipedia.org/wiki/Photovoltaics>.

[13] "Solar Panel Tracking Systems". DIY Renewable Energy - Home Solar Power Kits - Home Wind Turbine. $26 \quad$ May $2010 \quad<$ http://diyrenewableenergy.com/articles/solar panel- trackingsystems-2/>.

[14] http://www.instructables.com/id/ARDUINO-SOLARCHARGECONTROLLER-Version-30/?utmsource $=$ base $\& u t m-$ medium $=$ relatedinstructables \&utmcampaign $=$ related-test

[15] Muhammad H.Rashid, Power Electronics Circuits,Devices and Applications.

[16] Design of a Solar Tracker System for PV Power Plants, Tiberiu Tudorache, Liviu Kreindler, Acta Polytechnica Hungarica, Vol. 7, No. 1, 2010.

[17] Y. J. Huang, Member, IAENG, T. C. Kuo, Member, IAENG, C. Y. Chen, C. H. Chang, P. C. Wu, and T. H.
$\mathrm{Wu}$ "The Design and Implementation of a SolarTracking Generating Power System" Advance online publication: 19 November 2009, Engineering Letters, 17:4, EL-17-4-06

[18] Jahidul Islam Razan, Riasat Siam Islam, Rezaul Hasan, Samiul Hasan, and Fokhrul Islam "A Comprehensive Study ofMicro-Hydropower Plant and Its Potential in Bangladesh, International Scholarly Research Network ,ISRN Renewable Energy",Volume 2012, Article ID 635396, 10 pages ,doi:10.5402/2012/635396.

[19] Feasible Micro Hydro Potentiality Exploration in Hill Tracts of Bangladesh by By Khizir Mahmud, Md. Abu Taher Tanbir \& Md. Ashraful Islam.

[20] S. A. Keshavarz, P. Talebizadeh, S. Adalatia, M. A Mehrabian, M. Abdolzadeh "Optimal Slope-Angles to Determine Maximum Solar Energy Gain for Solar Collectors Used in Iran" INTERNATIONAL JOURNAL of RENEWABLE ENERGY RESEARCH P. Talebizadeh et al., Vol.2, No.4, 2012

[21] Arbi Gharakhani Siraki*, Pragasen Pillay "Study of Optimum Tilt Angle for Solar Panels in Different Latitudes for Urban Applications" Solar Energy 86(2012)1920-1928

[22] Amit Kumar Yadav, S. S. Chandel "Tilt Angle optimization to maximize incident solar radiation: a review" Renewable and Sustainable Energy Reviews 23(2013)503-513

\section{Author Profile}

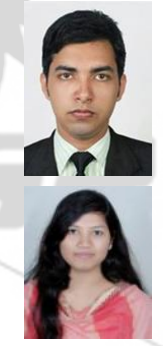

Bishwajit Swarnakar has Graduated from Department of Electrical and Electronic Engineering, Leading University, Sylhet in 2015.

Anupama Datta has Graduated from Department of Electrical and Electronic Engineering, Leading University, Sylhet in 2015. 